\title{
Factors Associated with Research Management in Australian Commerce and Business Faculties
}

\author{
Rob MacGregor*, Mark Rix, David Aylward and John Glynn \\ University of Wollongong, Australia
}

\begin{abstract}
Measurable research outputs have become part of the overall research management structure within Australian universities over the past ten years. As such, policy makers and administrators alike have come to regard effective management structures and mechanisms as fundamental components of a research environment capable of generating desired quantities of quality outcomes. This paper is based on empirical research carried out over the past year that surveyed academics from commerce and business faculties in Australian universities. The data show that factors such as gender, discipline, and academic level appear to impinge on the relative importance of components that make up research management.
\end{abstract}

\section{Introduction}

University academics have always worked in the dual roles of educator and researcher. Over the past two decades, the academic's role as a researcher has become more and more important, both as an indicator of how well the overall institution is perceived (Breslin \& Klagholz, 1980; Foldesi, 1996; Sutton \& Bergerson, 2001) and how well the individual academic is compensated (Fairweather, 1993; Lewis, 1996; Prewit, Philips, \& Yasin, 1991).

A number of studies in the US, Europe and, more recently, Australia (Benjamin, 1998; Marchant \& Newman, 1994; Rix, Aylward, MacGregor, \& Glynn, 2004; Taylor, Hunnicutt, \& Keeffe, 1991), have suggested the increasing emphasis on research as and individual and institutional indicator is a product of the reduction of the amount and control of funds to the university sector. While the number of students has grown, governments are increasingly demanding that universities spend public funds wisely and effectively and demonstrate their ability to attract significant external, non-government financial support for their activities, especially research.

*Corresponding author. University of Wollongong, Northfields Ave, Wollongong, NSW 2522, Australia. Email: rmacgreg@uow.edu.au 
In common with trends in the rest of the world, research management within Australian universities has over the past ten years become a priority for both policy makers and university administrators. Measurable research outputs increasingly determine the amount of public research funding received by institutions. Accordingly, policy makers and administrators alike have come to regard effective management structures and mechanisms as fundamental components of a research environment capable of producing desired outcomes. Studies in Australian universities have shown that in the past decade in particular, while growth in higher education has been matched by government demands for performance and quality, it has not been matched with any growth in government funding. Indeed, studies by Welsh and Metcalfe (2003) and Rix et al. (2004) have shown that the number of publications recognized by DEST (the Department of Education, Science and Training) produced by an institution's academic staff members in a year is an important factor in determining the amount of government research funding.

For academic staff in disciplines with high teaching loads (commerce, business, and technology) this "blanket” publication/funding equation adds additional pressure.

Research management procedures, processes and performance criteria have been put in place in most, if not all Australian universities. An examination of these procedures (Welsh \& Metcalfe, 2003; Wood \& Meek, 2002) shows that as with the government DEST model, most are applied across all faculties with little regard for range of teaching volumes and commitments. Not only do many of these procedures fail to acknowledge individual faculty differences, nor has there been sufficient rigorous examination as to how effective these procedures, processes and criteria are, either in terms of attracting external funding or improving performance (Jongbloed \& Vossensteyn, 2001). Further, there have been no studies examining the suitability of research management strategies to the staff who must work within them.

The motivation for this study was to examine the importance of factors that make up research management policies for academics in traditionally high-volume teaching areas. As such, this paper begins by briefly examining the role of research management policies, followed by an examination of changes in government policies in Australian universities and their effects on institutions and individuals. Finally, the paper provides some findings of a study of factors associated with research management carried out on 101 academics working within Commerce or Business faculties in Australian universities.

\section{The Role of Research Management Policies}

The aim of any research policy should be to enhance the future standing of both the institution as well as the individual academic. As such, Hearn (1999) suggests that policy needs to be discussed and supported before implementation. It must include decisions and procedures on how to react to the external marketplace, whether and what type of salary compensations are attached to the policy, who the stakeholders are in the policy realization and how to address conflict that might arise between those stakeholders. 
A number of authors (Diamond, 1993; Hearn, 1999; Sutton \& Bergerson, 2001) have suggested the following minimum criteria for the development of any research policy:

N The policies and procedures must fit within the mission of the institution (Diamond, 1993). For this alignment to occur, Sutton and Bergerson (2001) suggest that it requires the re-examination of the mission statement to ensure that it is realistically aligned to the characteristics and strengths of the individual institution.

N The policies and procedures must be sensitive to differences in disciplines within the institution. Sutton and Bergerson (2001) note that for some disciplines, teaching, consultation, or public service may take a greater role, while for others research is a primary concern and focus.

N Any policy or procedure must account for differences between individual academic staff members and must utilize strengths of individuals.

N Policy development must be mindful of accreditation demands placed on certain disciplines by either professional organizations or government bodies.

N All policies and procedures must have in-built assessments of all staff. These must be seen as fair and workable and must include mechanisms for the differences noted above.

N All policies and procedures must have self-assessment policies built into their structure such that policies are continually examined to determine whether they are adequate and suitable to both the institution as well as the individual.

\section{The Australian Situation}

In 2000, 695,485 students were enrolled in Australian universities, of which 37,158 were doing higher research degrees. Australian universities employed nearly 30,000 academic staff. The 37 public universities in the unified national system had a combined income of $\mathrm{A} \$ 9$ billion, $\$ 5$ billion of this revenue coming from Commonwealth operating grants (Wood \& Meek, 2002, p. 10). As Wood and Meek point out, however, funds from non-government sources have been growing as a proportion of total university revenues since the early 1990s (33\% in 1999). They note that this "is in line with government expectations regarding diversification of funding sources and 'user pays' regarding tertiary enrolments" (Wood \& Meek, p. 10). These reforms to higher education have had some intended, positive outcomes, including greater responsiveness of the sector to the needs of industry and the community, substantial increase in both domestic and international student numbers, an impressive increase in the number of graduates, and a dramatic decline in dependence on Commonwealth funding. However, there have also been some farreaching, negative consequences: "the high level of institutional competition has decreased the diversity of the system and stifled innovation; the corporatestyle institutional management encouraged by market-like competition tends to 
substantially alienate staff; and the decline in Commonwealth financial support threatens the quality of teaching and research in many institutions" (Wood \& Meek, p. 22; see also Bellamy, Morley, \& Watty, 2003; Lloyd, 2004).

In the ten years to 2003, the reforms to Australia's higher education sector outlined above had also brought about significant changes in research funding policy, forcing universities to identify and develop further their research strengths (DEST, 1999). One of the consequences of these changes has been the growth in numbers of university research "centres of excellence". The existence of such a centre is thought to provide compelling evidence of research strength in a particular field. (Zajkowski, 2003, p. 203). However, this was not the only significant change in the external environment affecting research funding and direction. Other important changes include:

N increased competition for research funding from ARC funding grant schemes and discretionary incomes such as the Research Training Scheme and Institutional Grants Scheme, and for research degree scholarships funded by the Commonwealth

N intensified competition for high quality national and international research students

I initiatives such as the Australian Government's "Backing Australia's Ability" review which seek to develop home-grown capacities to generate ideas and undertake productive research, facilitate any commercial applications of these ideas, and encourage the development and retention of skilled researchers

I an emphasis on moving from individual scholarship to institutional research activities in the arts, humanities, and social sciences (UoW, 2004, pp. 5-6).

Thomas (2000) suggests that these changes have had an effect both on the institution as well as the individual. At an institutional level, Thomas suggested that:

Over the last two decades many institutions of higher education have undertaken a fundamental review of their internal resource allocation mechanisms in response to environmental pressure. This has invariably involved two elements: an increasingly formulaic basis to resource allocation, often reflecting the methodology adopted by the national funding agency and enhanced devolution of budgetary responsibility to a departmental, school or faculty level. (Thomas, 2000, p. 127)

Thomas also noted that many of the steps taken included

new appointments at senior level (e.g. pro-vice-chancellor or deputy director) with a specific research brief; establishment of research committees as critical bodies within the institutional structure, reporting directly to the senate or academic board and determining the research agenda; devolution of financial responsibility to departments as an incentive for income generation; strategic allocation of pump-priming tools sometimes in the form of scholarships, to stimulate research; a requirement for annual reports on research activity; monitoring of output against faculty plans; establishment of 
research databases; targeting of refereed journals for publications; and the active search for research collaboration with partners already possessing a research reputation. (Thomas, 2001, p. 175)

At the individual level, Bellamy et al. (2003) found that despite the major reason given by academics to remain within the university system being flexibility and autonomy of employment, many research management policies

encouraged homogeneity across the university sector, rather than diversity as the government would have us believe. Additionally, academics at the local level may be able to isolate themselves to some extent from the mega-structural and political changes occurring at more senior levels in the system. Perhaps this finding supports the notion of a gap between policy development at the 'university centre' and policy implementation at the local level. (Bellamy et al., 2003, p. 27)

A number of studies (Bland \& Ruffin 1992; Pratt, Margaritis, \& Coy, 1999; Rix et al., 2004) have attempted to examine the factors that, at an individual level, affect research. A composite set is shown in Table 1 .

\section{Methodology}

A survey instrument was developed to collect data about the factors affecting research. Respondents were asked to rate each of the 16 factors (in Table 1) across a four-point Likert scale (very ineffective, ineffective, effective, very effective). The survey also contained questions used to build a profile of the respondents, including the gender, the academic level (Dean, Head of School/Discipline, Professor/ Associate Professor, Lecturer B/C, Associate Lecturer) and the Discipline.

Surveys were administered by telephone. A total of 101 academics were randomly chosen and interviewed.

Table 1. Factors affecting research

1. Effectiveness of the Faculty Research Management Structure

2. Whether it is linked to workloads models

3. Whether it nurtures new researchers

4. Whether it facilitates research

5. Whether it is transparent

6. How effective research communication mechanisms are within the faculty

7. Whether the faculty encourages interdisciplinary research

8. Whether the faculty encourages external research collaboration

9. Whether the current DEST indicators are relevant to an individual's own research

10. Whether the current DEST indicators direct individual research pursuits

11. To what extent the Faculty fosters research mentoring among staff

12. To what extent research students are included in Faculty research activities

13. How effective Quality Assurance mechanisms are

14. How clearly articulated the Faculty's research priority areas are

15. Whether research concentrations within your Faculty emerge naturally

16. Overall opinion of the research environment 


\section{Results and Findings}

All academics contacted by phone agreed to take part in the survey. The responses formed the basis for a statistical analysis carried out using SPSS. An inspection of the frequencies indicated that the full range of response scales was utilized by the respondents. The aim of the statistical analysis was to establish the correlation (if any) between the factors affecting research. Prior to this the scales of measurement for the 16 factors was tested using a Cronbach Alpha reliability test. Cronbach's Alpha was .7801, indicating a high level of reliability. An initial correlation matrix was produced (see Table 2). The correlation matrix indicated several "clusters" of questions or factors were in evidence.

The findings suggested the use of Factor Analysis to investigate any separate underlying factors and to reduce redundancy of certain questions indicated in the correlation matrix. The results of the Kaiser-Meyer-Olkin MSA (.761) and Bartlett's Test of Sphericity $\left(x^{2} 5584, \mathrm{p} 5.000\right)$ indicated that the data set satisfied the assumptions of factorability. Principle Component Analysis was chosen as the method of extraction in order to account for the maximum variance in the data using the minimum number of factors. A four-factor solution was extracted (see Table 3) with Eigenvalues of 4.530, 2.084, 1.605, and 1.199. This was supported by an inspection of the Scree Plots. These four factors accounted for $58.865 \%$ of the total variance. The four factors have been nominally termed research management, research nurturing, research indicators and research priorities.

The four resulting components were rotated using a Varimax procedure and a simple structure was achieved as shown in the Rotated Component matrix in Table 4.

Seven factors (Questions 1, 4, 5, 6, 7, 8, and 16) loaded highly on the first component (Research management), five factors (Questions 3, 4, 11, 12, and 13) loaded on the second component (Research nurturing), 3 factors (Questions 2, 9, and 10) loaded on the third component (research indicators) and 2 factors (Questions 14 and 15) loaded on the fourth component (Research priorities). The four factors are independent and uncorrelated, as an orthogonal procedure was used. It is interesting to note that Question 4 loaded onto components 1 and 2 (Research management and Research nurturing) although the loading was slightly higher for research management.

The data were then separately subdivided by gender, academic level, and discipline. For each set of subdivisions correlation matrices were produced and a similar set of factor analyses was performed (these are available from the authors). The resultant Eigenvalues and percentage of variance provide an indicator of the relative importance of each of the factors to the sample subgroups. Tables 5 to 7 show the relative levels of importance of the four factors for the subgroups. It should be noted that the tables do not add to $100 \%$ as the ratings by some respondents may be loaded onto more than one factor. 
Table 2. Correlation matrix of factors affecting research

\begin{tabular}{|c|c|c|c|c|c|c|c|c|c|c|c|c|c|c|c|}
\hline & Q1 & Q2 & Q3 & Q4 & Q5 & Q6 & Q7 & Q8 & Q9 & Q10 & Q11 & Q12 & Q13 & Q14 & Q15 \\
\hline Q2 & .167 & & & & & & & & & & & & & & \\
\hline Q3 & $.207^{*}$ & $.220 *$ & & & & & & & & & & & & & \\
\hline Q4 & .375 & .044 & $.283^{* *}$ & & & & & & & & & & & & \\
\hline Q5 & .392 & .173 & $.299 * *$ & .473 & & & & & & & & & & & \\
\hline Q6 & .445 & .106 & $.219 *$ & .455 & .567 & & & & & & & & & & \\
\hline Q7 & .319 & .124 & .116 & $.261^{* *}$ & $.292 * *$ & .329 & & & & & & & & & \\
\hline Q8 & .439 & .068 & .158 & .339 & .397 & .384 & .481 & & & & & & & & \\
\hline Q9 & .102 & $.302 * *$ & $.230 *$ & 2.013 & .173 & .130 & 2.036 & .044 & & & & & & & \\
\hline Q10 & .111 & $.285^{* *}$ & .192 & .032 & .076 & .144 & .025 & .101 & .834 & & & & & & \\
\hline Q11 & $.234^{*}$ & .072 & .313 & .573 & .327 & .320 & .344 & $.279 * *$ & .055 & .086 & & & & & \\
\hline Q12 & .004 & 2.065 & .064 & $.199 *$ & .192 & .138 & $.214^{*}$ & .134 & 2.097 & 2.116 & $.290 * *$ & & & & \\
\hline Q13 & 2.036 & .178 & .337 & .350 & $.284^{* *}$ & .113 & .320 & .169 & .131 & .135 & .502 & .355 & & & \\
\hline Q14 & .160 & .029 & .171 & $.305^{* *}$ & .119 & .105 & $.200 *$ & .068 & 2.022 & .024 & $.280 * *$ & $.231 *$ & .176 & & \\
\hline Q15 & 2.043 & .054 & 2.054 & 2.071 & .017 & $2.268 * *$ & .168 & 2.016 & .058 & .028 & .070 & .090 & .048 & $.219 *$ & \\
\hline Q16 & .474 & $.238 *$ & .398 & .521 & .524 & .508 & .435 & .435 & 2.025 & .050 & .473 & .172 & .326 & $.295 * *$ & 2.012 \\
\hline
\end{tabular}

* .05

**. 01 
Table 3. Total variance explained

\begin{tabular}{lccc}
\hline Component & Eigenvalue & \% of variance & Cumulative \% \\
\hline research management & 4.530 & 28.315 & 28.315 \\
research nurturing & 2.084 & 13.026 & 41.340 \\
research indicators & 1.605 & 10.034 & 51.374 \\
research priorities & 1.199 & 7.491 & 58.865 \\
\hline
\end{tabular}

Table 4. Rotated component matrix

\begin{tabular}{lcccc}
\hline & $\begin{array}{c}\text { Research } \\
\text { management }\end{array}$ & $\begin{array}{c}\text { Research } \\
\text { nurturing }\end{array}$ & $\begin{array}{c}\text { Research } \\
\text { indicators }\end{array}$ & $\begin{array}{c}\text { Research } \\
\text { priorities }\end{array}$ \\
\hline Q1 & .785 & 2.009 & .117 & .004 \\
Q2 & .162 & .004 & .538 & .010 \\
Q3 & .203 & .487 & .345 & 2.192 \\
Q4 & .537 & .532 & 2.004 & 2.118 \\
Q5 & .634 & .315 & .148 & 2.009 \\
Q6 & .728 & .175 & .009 & .313 \\
Q7 & .565 & .207 & .002 & .451 \\
Q8 & .714 & .004 & .003 & .152 \\
Q9 & 2.008 & .007 & .917 & 2.003 \\
Q10 & .003 & .005 & .895 & .002 \\
Q11 & .325 & .696 & .005 & .192 \\
Q12 & .002 & .589 & 2.219 & .007 \\
Q13 & .001 & .803 & 2.175 & .426 \\
Q14 & .151 & .399 & 2.003 & .852 \\
Q15 & 2.106 & .002 & .010 & .004 \\
Q16 & .699 & .406 & .004 & \\
\hline
\end{tabular}

Table 5. Importance of each of the research factors by gender

\begin{tabular}{lrr}
\hline Importance & Male & Female \\
\hline Research management & $30.608 \%$ & $14.195 \%$ \\
Research nurturing & $8.298 \%$ & $28.398 \%$ \\
Research indicators & $10.669 \%$ & $9.253 \%$ \\
Research priorities & $15.580 \%$ & $8.559 \%$ \\
\hline
\end{tabular}

Table 6. Importance of each of the research factors by level

\begin{tabular}{lrcrrr}
\hline & & $\begin{array}{c}\text { Head of } \\
\text { Dept. or } \\
\text { Importance }\end{array}$ & $\begin{array}{c}\text { Junior } \\
\text { Lecture } \\
\text { (Lecturer A) }\end{array}$ & $\begin{array}{c}\text { Senior } \\
\text { Lecturer } \\
\text { (Lecturer B/C) }\end{array}$ & $\begin{array}{c}\text { Prof/Assoc. } \\
\text { Prof }\end{array}$ \\
\hline Research management & $45.166 \%$ & $38.233 \%$ & $14.378 \%$ & $28.013 \%$ & $28.193 \%$ \\
Research nurturing & $6.671 \%$ & $16.321 \%$ & $26.410 \%$ & $14.015 \%$ & $9.084 \%$ \\
Research indicators & $20.555 \%$ & $15.360 \%$ & $17.318 \%$ & $11.324 \%$ & $22.864 \%$ \\
Research priorities & $14.238 \%$ & $10.251 \%$ & $10.595 \%$ & $7.745 \%$ & $14.674 \%$ \\
\hline
\end{tabular}


Table 7. Importance of each of the research factors by discipline

\begin{tabular}{lrrrrrr}
\hline \multirow{2}{*}{ Importance } & \multicolumn{3}{c}{ Information } & \\
\hline Research management & Accountancy & Economics & Systems & Law & Marketing Management \\
Research nurturing & $8.564 \%$ & $15.203 \%$ & $6.822 \%$ & & $29.889 \%$ & $32.050 \%$ \\
Research indicators & $21.667 \%$ & $22.361 \%$ & $22.624 \%$ & $23.867 \%$ & $20.408 \%$ & $12.931 \%$ \\
Research priorities & $8.170 \%$ & $10.062 \%$ & $10.203 \%$ & $7.576 \%$ & $10.146 \%$ & $8.391 \%$ \\
\hline
\end{tabular}

* Law respondents considered Research management and Research nurturing to be one component

\section{Discussion}

The results of this study are an important first step in consolidating our understanding of factors affecting research in Australian universities. The correlations and subsequent factor analyses indicate that factors can be grouped into four main themes - research management, research nurturing, research indicators and research priorities. An examination of Table 4 shows that research management includes facilitation of research, transparency of research management, communication of policy, and collaboration. Research nurturing includes facilitation of research, mentoring, encouragement of research students, and quality assurance of research supervision. The factor research indicators includes workloads models and research priorities includes details of how concentrations of research are arrived at.

An examination of Table 3 shows that for the entire respondent population, the strongest research factor is research management, accounting for $28.315 \%$ of the variance in responses. Indeed, this factor is more than twice as important as any of the other factor.

Table 5 shows the respondent data subdivided by gender. An examination of the data shows that the most important factor for male respondents appears to be research management. $30.608 \%$ of the variance found in the factor analysis for males was attributable to research management. By comparison, the largest variance for females was research nurturing. Clearly, then, there are distinct gender differences in the perception of the relative importance of research factors.

Table 6 presents the respondent data subdivided by level within the university. An examination of Table 6 shows that with the exception of Lecturer A respondents, all levels considered research management to be the single most important factor. Staff at this level considered the need for research nurturing to be more important. It is interesting to note that at the highest levels, Executive and Professor/Associate Professor, the second most important research factor was research indicators.

Table 7 presents the respondent data subdivided by discipline. An examination of the data shows that three disciplines, Accountancy, Economics, and Information Systems considered research management to be the most important factor, with research indicators being the second most important. By comparison, Management and Marketing considered research nurturing to be far more important than research 
management. Of particular interest are the responses from the Law discipline that considered research nurturing to be part of research management.

The results of this study are significant both for government and university administrations promoting research within their campuses. First, the basic model reduces fragmentation from having a large number of factors concerned with research. It also provides a more concise understanding of research and research factors because 16 factors can be grouped into four factors. This is powerful explanatory tool because research factors can now be explained in terms of research management, research nurturing, research indicators and research priorities.

The study is also important because it shows that a number of underlying considerations are "at work" in the discussion of research factors. These include gender, academic level, and discipline. This is an important finding for government and university administrators. Clearly, the results suggest that any attempt to promote research needs to be mindful of these underlying considerations.

\section{Limitations}

It should be noted that the study presented here has several limitations. First, the number of respondents was only 101, making any attempt to generalize the findings problematic. Further similar studies need to be undertaken before any generalizable findings are possible Second, the choice of variables could change over time or through amendments to government policy, thus altering the alignment of these to the four factors. Finally, a far more in-depth qualitative analysis needs to be undertaken to determine the impact the four factors have on research and why certain subgroups of the university population rate various factors differently to other subgroups.

\section{Conclusion}

The higher education policies of the Commonwealth Government have been enormously influential in shaping the research environment within Australian universities. As university administrators have sought to integrate research planning at the faculty level with planning at the institutional level, so have government policies had a direct and often severe impact on the working lives of Australian academics. These developments have put considerable pressure on individual academics to lift their own "research game". These pressures appear to have been greatest in commerce and business faculties that have experienced the combined effects of higher teaching volumes and detailed, micro-management and measurement of research performance. Accordingly, research management within these faculties has to be undertaken with great care to ensure that it does in fact encourage research and improve research performance in an environment not always conducive to research. It is hardly surprising that commerce and business faculty staff rate research management factors as the factor having 
the greatest impact on their research. However, as the research reported in this paper has demonstrated, the effectiveness of research management in commerce and business faculties was rated quite differently across the demographic categories identified.

\section{References}

Bellamy, S., Morley, C., \& Watty, K. (2003). Why business academics remain in Australian universities despite deteriorating working conditions and reduced job satisfaction: An intellectual puzzle. Journal of Higher Education Policy and Management, 25(1), 13-28.

Benjamin, R. (1998). Salary Systems in Public Higher Education. New York: Praeger.

Bland, C. P., \& Ruffin, M. T. (1992). Characteristics of a productive research environment: Literature review. Academic Medicine, 67(6), 385-397.

Breslin, R. D., \& Klagholz, L. F. (1980). Paying faculty members what they're worth. Educational Record, 61(1), 43-44.

Department of Education, Science and Training (DEST) (1999) Retrieved April 16, 2004, from http://www.dest.gov.au/archive/highered/whitepaper/3.htm

Diamond, R. M. (1993). Changing priorities and the faculty reward system. In R. M. Diamond, \& B. E. Adams (Eds.), Recognizing Faculty Work: Rewards systems for the year 2000 (pp. 5-12). San Francisco: Jossey Bass.

Fairweather, J. S. (1993). American values and faculty rewards. Review of Higher Education, 17(1), 43-68.

Foldesi, R. S. (1996). Higher education compensation systems for the future. CUPA Journal, 47(2), 29-32.

Hearn, J. C. (1999). Pay and performance in the university: An examination of faculty salaries. Review of Higher Education, 22(4), 391-410.

Jongbloed, B., \& Vossensteyn, H. (2001). Keeping up performance: An international survey of performance-based funding in higher education. Journal of Higher Education Policy and Management, 23(2), 127-145.

Lewis, L. S. (1996). Marginal Worth: Teaching and the academic labour market. New Jersey: Transaction Publishers.

Lloyd, D. (2004, March 24-30). Time to get serious about diversity. Campus Review, p. 2.

Marchant, G. J., \& Newman, I. (1994). Faculty activities and rewards: Views from education administrators in USA. Assessment an Evaluation in Higher Education, 19(2), 145-152.

Pratt, M., Margaritis, D., \& Coy, D. (1999). Developing a research culture in a university faculty. Journal of Higher Education Policy and Management, 21(1), 43-55.

Prewit, L. B., Phillips, J. D., \& Yasin, K. (1991). Merit pay in academia: Perceptions from the school of business. Public Personnel Management, 20(4), 409-417.

Rix, M., Aylward, D., MacGregor, R., \& Glynn, J. (2004, September 2-3). The effectiveness of research structures and mechanisms within Australian commerce faculties: A user perspective. Paper presented at the Irish Academy of Management Conference, Dublin, Ireland.

Sutton, T. P., \& Bergerson, P. J. (2001). Faculty Compensation Systems: Impact on the quality of higher education. Washington, DC: Office of Educational Research and Improvement.

Taylor, R. L., Hunnicutt, G. G., \& Keeffe, M. J. (1991). Merit pay in academia: Historical perspectives and contemporary perceptions. Review of Public Administration, 11(3), 51-65.

Thomas, H. (2000). Power in the resource allocation process: The impact of 'rational' systems. Journal of Higher Education Policy and Management, 22(2), 127-137.

Thomas, H. G. (2001). Funding mechanism or quality assessment: Responses to the research assessment exercise in English institutions. Journal of Higher Education Policy and Management, 23(2), 183-193. 
University of Wollongong (UoW) (2004, March). Research Management Strategic Plan 2003-2006 (draft). Wollongong, Australia: University of Wollongong.

Welsh, J., \& Metcalf, J. (2003). Administrative support for institutional effectiveness activities: Response to the new accountability. Journal of Higher Education Policy and Management, 25(2), $171-179$.

Wood, F., \& Meek, L. (2002). Over-reviewed and underfunded? The evolving policy context of Australian higher education research and development. Journal of Higher Education Policy and Management, 24(1), 7-25.

Zajkowski, M. E. (2003). Institutional structure and the Australian research director: A qualitative study. Journal of Higher Education Policy and Management, 25(2), 203-212. 